\title{
Factors affecting outcome in frameless non-isocentric stereotactic radiosurgery for trigeminal neuralgia: a multicentric cohort study
}

\author{
Alfredo Conti ${ }^{1,2,3^{*}+}$, Gueliz Acker ${ }^{1,2,4 \dagger}$, Antonio Pontoriero ${ }^{5}$, Juliane Hardt ${ }^{6,7,8}$, Anne Kluge ${ }^{2,9}$, Alberto Cacciola ${ }^{5}$, \\ Giuseppe lati ${ }^{5}$, Markus Kufeld ${ }^{2}$, Volker Budach ${ }^{2,9}$, Peter Vajkoczy ${ }^{1,2}$, Giancarlo Beltramo ${ }^{10}$, Stefano Pergolizzi ${ }^{5}$, \\ Achille Bergantin ${ }^{10}$, Franziska Loebel ${ }^{1,2}$, Silvana Parisi ${ }^{5}$, Carolin Senger ${ }^{2,9 \dagger}$ and Pantaleo Romanellii ${ }^{10 \dagger}$
}

\begin{abstract}
Background: Stereotactic radiosurgery (SRS) is an effective treatment for trigeminal neuralgia (TN). Nevertheless, a proportion of patients will experience recurrence and treatment-related sensory disturbances. In order to evaluate the predictors of efficacy and safety of image-guided non-isocentric radiosurgery, we analyzed the impact of trigeminal nerve volume and the nerve dose/volume relationship, together with relevant clinical characteristics.

Methods: Two-hundred and ninety-six procedures were performed on 262 patients at three centers. In 17 patients the TN was secondary to multiple sclerosis (MS). Trigeminal pain and sensory disturbances were classified according to the Barrow Neurological Institute (BNI) scale. Pain-free-intervals were investigated using Kaplan Meier analyses. Univariate and multivariate Cox regression analyses were performed to identify predictors.

Results: The median follow-up period was 38 months, median maximal dose $72.4 \mathrm{~Gy}$, median target nerve volume $25 \mathrm{~mm}^{3}$, and median prescription dose $60 \mathrm{~Gy}$. Pain control rate (BNI I-III) at 6, 12, 24, 36, 48, and 60 months were $96.8,90.9,84.2,81.4,74.2$, and $71.2 \%$, respectively. Overall, $18 \%$ of patients developed sensory disturbances. Patients with volume $\geq 30 \mathrm{~mm}^{3}$ were more likely to maintain pain relief $(p=0.031)$, and low integral dose $(<1.4 \mathrm{~mJ})$ tended to be associated with more pain recurrence than intermediate $(1.4-2.7 \mathrm{~mJ})$ or high integral dose $(>2.7 \mathrm{~mJ}$; low vs. intermediate: log-rank test, $X^{2}=5.02, p=0.019$; low vs. high: log-rank test, $\left.X^{2}=6.026, p=0.014\right)$. MS, integral dose, and mean dose were the factors associated with pain recurrence, while re-irradiation and MS were predictors for sensory disturbance in the multivariate analysis.

(Continued on next page)
\end{abstract}

\footnotetext{
* Correspondence: alfredo.conti2@unibo.it

${ }^{+}$Alfredo Conti, Gueliz Acker, Carolin Senger and Pantaleo Romanelli

contributed equally to this work.

'Department of Neurosurgery, Charité - Universitätsmedizin Berlin, corporate member of Freie Universität Berlin, Humboldt-Universität zu Berlin and Berlin Institute of Health, Charitéplatz 1, 10117 Berlin, Germany

${ }^{2}$ Charité CyberKnife Center, Charité - Universitätsmedizin Berlin,

Augustenburger Platz 1, Berlin 13353, Germany

Full list of author information is available at the end of the article
}

(C) The Author(s). 2020 Open Access This article is licensed under a Creative Commons Attribution 4.0 International License, which permits use, sharing, adaptation, distribution and reproduction in any medium or format, as long as you give appropriate credit to the original author(s) and the source, provide a link to the Creative Commons licence, and indicate if changes were made. The images or other third party material in this article are included in the article's Creative Commons licence, unless indicated otherwise in a credit line to the material. If material is not included in the article's Creative Commons licence and your intended use is not permitted by statutory regulation or exceeds the permitted use, you will need to obtain permission directly from the copyright holder. To view a copy of this licence, visit http://creativecommons.org/licenses/by/4.0/. The Creative Commons Public Domain Dedication waiver (http://creativecommons.org/publicdomain/zero/1.0/) applies to the data made available in this article, unless otherwise stated in a credit line to the data. 
(Continued from previous page)

Conclusions: The dose to nerve volume ratio is predictive of pain recurrence in $\mathrm{TN}$, and re-irradiation has a major impact on the development of sensory disturbances after non-isocentric SRS. Interestingly, the integral dose may differ significantly in treatments using apparently similar dose and volume constraints.

Keywords: CyberKnife, Neuropathic pain, Stereotactic radiosurgery, Trigeminal neuralgia, Neuropathic pain

\section{Background}

Trigeminal neuralgia (TN) is the most common craniofacial pain syndrome. Medical therapy, usually based on carbamazepine, is the first treatment option, but effective pain control often requires doses associated with severe side effects. Surgical treatment option is considered when drug therapy deems ineffective in controlling pain and/or causes severe side effects [1]; thus, surgery is often necessary. In case of a neurovascular conflict, the first line treatment is microvascular decompression (MVD), which can result in up to $100 \%$ initial pain relief [2-5]. Nonetheless, this technique is not always applicable due to a lack of neurovascular conflict, contraindications for major surgery, or patient preference. Alternative techniques aim to modulate the trigeminal nociceptive pathways either by percutaneous lesioning of the Gasserian ganglion or by irradiation of the cisternal portion of the nerve using stereotactic radiosurgery (SRS) $[1,6,7]$. Clinical experience regarding $\mathrm{TN}$ treatment using SRS is based mainly on single isocenter Gamma knife radiosurgery (GKS) treatments [8]. Typically GKS results in up to $92 \%$ pain relief within 12 months; however, the pain relapse rate during follow-up is remarkable [9-17]. Alternatively, radiosurgical rhizotomy can be performed using a frameless image-guided robotic technique with the CyberKnife system (CKS) to irradiate an individually contoured segment of the trigeminal nerve by delivering non-isocentric radiation beams [18-20]. So far, reported clinical results of CKS seem to be satisfactory, with initial pain relief reported in 67.0 to $97.8 \%$ of the patients [7, 21, 22]. As with the GKS series, pain relapse is the major pitfall of the radiosurgical treatments, with pain control decreasing over time [7]. The ratio of dose to nerve volume, smaller nerve volume, and low prescribed dose have been claimed as potential predictors for treatment failure after SRS [7, 23, 24]; however, large cohort studies analyzing radiation metric factors interfering with the outcome in non-isocentric SRS for TN are yet to be reported. Thus, there is a lack of evidence for standardized therapy algorithms that include the selection of relevant radiosurgical treatment parameters such as dose to the target, target nerve volume, and prescription isodose.

The aim of our study was to evaluate predictors of efficacy and safety of image-guided robotic radiosurgery in a large multicentric patient cohort.

\section{Methods}

\section{Setting and study design}

The patient data were retrospectively analyzed; thus, consent forms were deemed unnecessary. Data were pooled from two Italian (centers A and B: CDI Centro Diagnostico Italiano, Milan and Department of Radiation Oncology, University of Messina, Messina) and one German (center C: CyberKnife Center, Charité - Universitätsmedizin Berlin) centers. The retrospective analysis was approved by the Ethics Committee Campus Charité Mitte (EA1/233/18) and by Comitato Etico Interaziendale Messina (80/19).

\section{Participants}

Patients with TN, as defined by the International Headache Society (2003), who were treated using nonisocentric, image-guided robotic radiosurgery for medically resistant pain between 2010 and 2016 (center A), 2013-2018 (center B), and 2011-2018 (center C) were included in this study.

\section{Variables}

We gathered data regarding the presence of multiple sclerosis (MS), re-irradiation, decision making for SRS, clinical outcome, and therapy-associated morbidity with a focus on sensory dysfunctions. Mean and maximal treatment dose $\left(D_{\text {mean }}, D_{\text {max }}\right)$, target nerve volume, prescription dose (PD), and integral dose (ID, calculated as target nerve volume $\times$ mean dose) were the parameters investigated.

\section{Radiosurgery treatment}

Patients were treated with SRS using a CyberKnife system (Accuray Inc., Sunnyvale, California) as described before [7]. The treatment was planned using MultiPlan (Accuray Inc.) on a native computed tomography (CT) scan $(120 \mathrm{kV}$, slice thickness: $\leq 1.0 \mathrm{~mm})$ and coregistered constructive interference in steady state (CISS) magnetic resonance (MR) images (T2-weighted, $3 \mathrm{D}$ gradient echo technique, isotropic voxel size: $\leq 1.0 \times$ $1.0 \times 1.0 \mathrm{~mm}^{3}$ ) (Fig. 1). The target nerve volume includes the complete nerve diameter over an interindividual nerve length, typically $5-6 \mathrm{~mm}$ of the cisternal portion of the trigeminal nerve outlined, depending on the patient's anatomy. The $80 \%$ isodose line was then prescribed, encompassing the contoured nerve volume between the root entry zone and the area where the nerve leaves the intracranial space to enter the Meckel's 


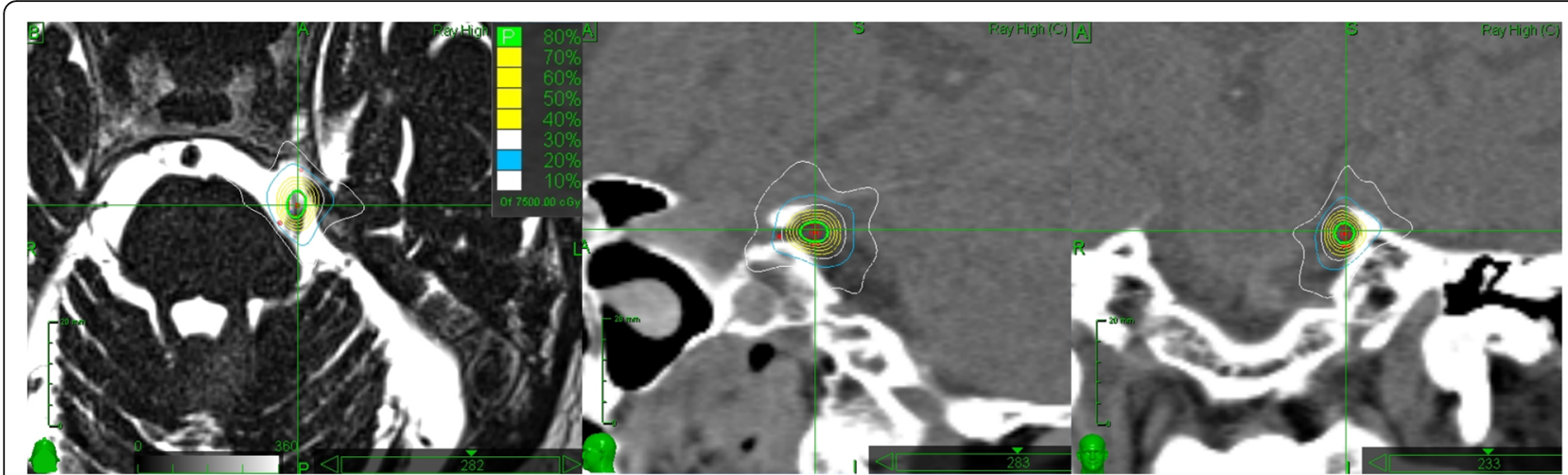

Fig. 1 Typical CyberKnife stereotactic dose distribution for trigeminal neuralgia targeted at the cisternal portion of the nerve. left: MR CISS weighted axial image, middle and right: sagittal and coronal CT images. The dose is typically 60 Gy prescribed to the $80 \%$ isodose line

cave, while keeping a certain distance to the brainstem and temporal lobe. The treatment dose was selected according to each hospital standard. Dose constraints to organs at risk (OAR) were as follows: $<0.50 \mathrm{~cm}^{3}$ of the brainstem was allowed to receive $10.0 \mathrm{~Gy}$ with a maximum dose of $15.0 \mathrm{~Gy}$ in $\leq 0.035 \mathrm{~cm}^{3}$ and $\leq 0.035 \mathrm{~cm}^{3}$ of the temporal lobe was allowed to receive a maximum dose of $35.0 \mathrm{~Gy}$. Treatment dose or volume was adjusted if the OAR constraints were not applicable due to individual trigeminal nerve anatomy or cisternal narrowness.

Treatment planning, determination of target and dose, and treatment delivery are described in detail in Additional file 1.

\section{Outcome assessment}

Clinical follow-up was carried out 3-6 months after CKSRS and then once yearly. The latest follow-up was included in this study. The focus of the follow-up was to verify the pain relief and new onset of facial numbness; accordingly, the endpoints analyzed were: i) pain relief, ii) occurrence of sensory disturbance, and iii) rate of pain recurrence.

\section{Quantitative variables}

Pain and hypoesthesia evaluation were scored using the Barrow Neurological Institute (BNI) scales for pain I-V and for hypoesthesia I-IV, respectively [25]. We dichotomized the pain response as sufficient or inadequate after treatment as BNI grades I-IIIb and IV-V, respectively. Similarly, non-significant or bothersome numbness were categorized as BNI grades I-II and III-IV, respectively. Any consecutive trigeminal motor deficits were recorded.

\section{Statistical methods}

Overall, the entire pain-free interval was examined using Kaplan Meier analysis. Pain-free intervals for 6, 12, 24, 36,48 , and 60 months were calculated. Group comparison was carried out using the log-rank test. In order to assess risk factors potentially associated with pain relapse or occurrence of numbness, univariate and multivariate Cox regression analyses were performed using clinically selected variables. The selection process of variables for the multiple regression model included two steps as described before [26].

The treatment parameters were reported as mean (standard deviation [SD]) and median. SPSS version 25.0. (Armonk, NY; IBM Corp.) was used for statistical analyses.

As this was an exploratory study where a series of group comparisons, regression analyses, and tests of normal distribution for continuous variables were performed, the twosided $p$-values, described as significant if $<0.05$, are meant as indicators and should not be interpreted as confirmatory.

\section{Results}

\section{Participants}

Patient characteristics are listed in Table 1. A total of 296 TN treatments in 262 patients were included in the analysis. Center A included 144 patients (55\%), center B included 79 patients (30.2\%), and center C included 39 patients (14.8\%). Accordingly, 34 patients (13\%) needed CyberKnife-SRS re-irradiation. We analyzed the decisionmaking process for selecting CyberKnife-SRS instead of MVD. The most crucial reasons were missing nerve/vessel conflicts on MR images and age of the patients (age $\geq 75$ years), followed by personal preference (Fig. 2).

There was overall a minor female predominance (1.4:1.0). MS was diagnosed in $6.5 \%(n=17)$ of the patients. The median age at therapy was 64 years (range 22-91 years).

A follow-up with at least 3 months intervals was possible in $96 \%$ of the cases. The median follow-up time to last contact was 38 months (range 0.7-117 months).

\section{Main results}

\section{Radiosurgical parameters}

The treatment plans and target nerve volume, PD, $D_{\text {mean }}, D_{\text {max }}$, and ID data for the three different institutions are summarized in Table 2. The treatment 
Table 1 Patient demographic characteristics

\begin{tabular}{|c|c|c|c|c|}
\hline & Total & Center A & Center B & Center C \\
\hline Treatments (Patients) & $296(262)$ & $176(144)$ & $80(79)$ & $40(39)$ \\
\hline \multicolumn{5}{|l|}{ Sex } \\
\hline Male & $42.9 \%$ & $44.3 \%$ & $42.5 \%$ & $37.5 \%$ \\
\hline Female & $57.1 \%$ & $55.7 \%$ & $57.5 \%$ & $62.5 \%$ \\
\hline \multicolumn{5}{|c|}{ Age at treatment (years) } \\
\hline Median (range) & $63.8(22.4-91.4)$ & $60.5(22.4-89.2)$ & $66.9(40.7-88.1)$ & $66.1(40.9-91.4)$ \\
\hline \multicolumn{5}{|l|}{ Follow-up (months) } \\
\hline Mean (SD) & $40.7(29.0)$ & $38.4(20.4)$ & $58.3(36.6)$ & $16.4(16.6)$ \\
\hline Median (range) & $38.0(0.7-117.0)$ & $38.4 .0(3.7-79.3)$ & $49.0(3.0-117.0)$ & $8.0(0.7-66.1)$ \\
\hline Re-irradiation (n) & 34 & 32 & 1 & 1 \\
\hline MS (n) & 17 & 8 & 0 & 9 \\
\hline
\end{tabular}

parameters were overall comparable in the three centers, with differences in volume, $\mathrm{D}_{\max }$, and ID.

\section{Response of TN to primary CKS}

For this analysis, we focused on the response to the first SRS treatment and excluded the retreated patients. Actuarial pain control rates could be acquired in $88.2 \%$ of the cases (231 patients). In $54.1 \%$ of the patients, full pain control (BNI I) could be achieved (Table 3). Estimated pain control rates (BNI class I-III) at 6, 12, 24, 36, 48 , and 60 months were 96.8, 90.9, 84.2, 81.4, 74.2, and $71.2 \%$, respectively (Fig. 3). Facial numbness as a side effect occurred in $18 \%$ of patients.

\section{Re-irradiation}

We identified 34 SRS re-irradiations in our cohort. None of the retreated patients had MS. The majority of the patients $(70 \%)$ suffered from new onset numbness after reirradiation. Actuarial pain control rates (BNI class I-III) for re-irradiation at $6,12,24,36,48$, and 60 months were $91.2,88.1,88.1,88.1,79.8$, and $79.8 \%$, respectively (Fig. 3). There was, however, no statistically significant difference compared to primary therapy.

\section{Predictors for treatment outcome Pain relief}

Univariate Cox regression analyses showed that lower ID, smaller nerve volume, and presence of MS were associated with treatment failure (Table 4). With regard to multicollinearity, we had to decide between $\mathrm{D}_{\text {mean }}, \mathrm{D}_{\max }$ ID, and volume for inclusion in the multivariate analysis. We chose mean ID based on clinical interest. In multivariate analysis, lower ID and presence of MS were the major predictors for treatment failure, while higher mean dose also emerged as a significant predictor with a slightly higher risk for pain recurrence. With regard to pain as the outcome, the multivariate Cox regression model was comparable when patients with re-irradiation and/or MS were excluded (ID: hazard ratio [HR] $=0.517$, confidence interval $[\mathrm{CI}]=0.354-0.756) ; \mathrm{D}_{\text {mean }}$ : $\mathrm{HR}=$

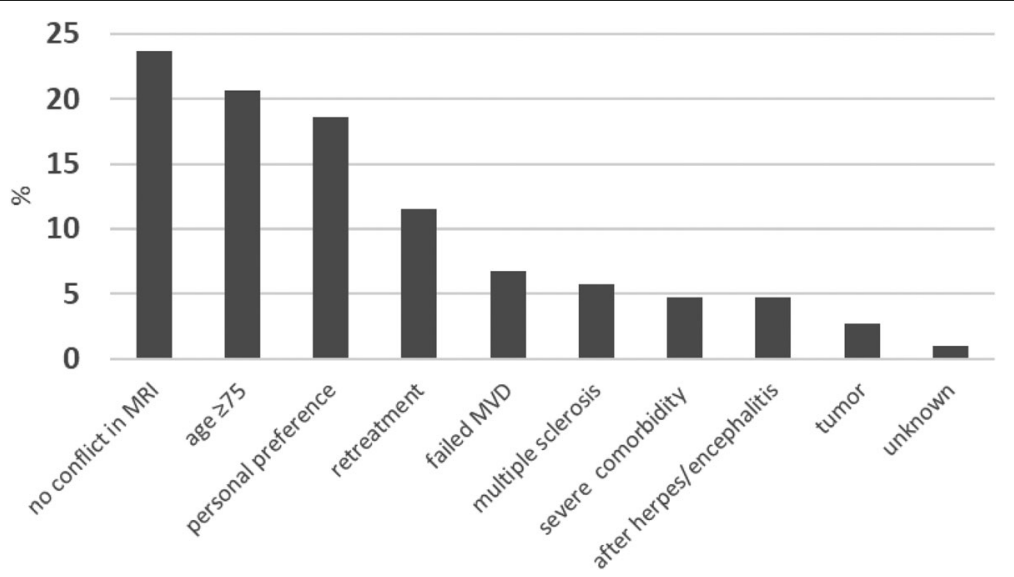

Fig. 2 An overview of the indications for CyberKnife stereotactic radiosurgery instead of microvascular decompression (MVD) 
Table 2 Summary of treatment parameters in the three centers

\begin{tabular}{|c|c|c|c|c|c|c|}
\hline & & $n$ & Mean (SD) & Median & Min & Max \\
\hline \multirow[t]{4}{*}{ Volume $\left(\mathrm{mm}^{3}\right)$} & Center A & 176 & $29.0(14.3)$ & 25.0 & 5.0 & 103.3 \\
\hline & Center B & 80 & $27.7(12.3)$ & 30.0 & 10.0 & 70.0 \\
\hline & Center C & 40 & $23.8(12.8)$ & 20.0 & 10.0 & 60.5 \\
\hline & Overall & 296 & $28.0(13.7)$ & 25.0 & 5.0 & 103.3 \\
\hline \multirow[t]{4}{*}{ Prescription dose (Gy) } & Center A & 176 & $57.7(6.7)$ & 60.0 & 35.0 & 90.0 \\
\hline & Center B & 80 & $57.4(2.6)$ & 58.0 & 38.0 & 60.0 \\
\hline & Center C & 40 & $60.2(4.1)$ & 60.0 & 49.0 & 70.0 \\
\hline & Overall & 296 & $58.0(5.6)$ & 60.0 & 35.0 & 90.0 \\
\hline \multirow[t]{4}{*}{ Isodose (\%) } & Center A & 176 & $83.0(3.2)$ & 83.0 & 73.0 & 90.0 \\
\hline & Center B & 80 & $80.0(0.4)$ & 80.0 & 78.0 & 80.0 \\
\hline & Center C & 40 & $80.0(3.2)$ & 80.0 & 70.0 & 85.0 \\
\hline & Overall & 296 & $81.6(3.1)$ & 80.0 & 70.0 & 90.0 \\
\hline \multirow[t]{4}{*}{$D_{\max }(G y)$} & Center A & 176 & $70.0(8.1)$ & 71.3 & 42.7 & 112.5 \\
\hline & Center B & 80 & $72.0(3.3)$ & 72.5 & 47.5 & 75.0 \\
\hline & Center C & 40 & $75.7(4.0)$ & 75.0 & 70.0 & 87.5 \\
\hline & Overall & 296 & $71.1(7.0)$ & 72.4 & 42.7 & 112.5 \\
\hline \multirow[t]{4}{*}{$D_{\text {mean }}(G y)$} & Center A & 176 & $63.7(7.3)$ & 65.3 & 38.8 & 101.3 \\
\hline & Center B & 80 & $64.7(2.9)$ & 65.3 & 42.8 & 67.5 \\
\hline & Center C & 40 & $68.1(3.8)$ & 67.5 & 59.8 & 80.1 \\
\hline & Overall & 296 & $64.5(6.2)$ & 65.3 & 38.8 & 101.3 \\
\hline \multirow[t]{4}{*}{ Integral dose (mJ) } & Center A & 176 & $2.0(0.9)$ & 1.6 & 0.3 & 6.7 \\
\hline & Center B & 80 & $1.8(0.8)$ & 1.9 & 0.6 & 4.4 \\
\hline & Center C & 40 & $1.6(0.8)$ & 1.4 & 0.7 & 4.0 \\
\hline & Overall & 296 & $1.8(0.9)$ & 1.6 & 0.3 & 6.7 \\
\hline
\end{tabular}

1.038, CI $=0.999-1.079$ ). The probability of maintaining pain relief was then compared according to the categorized treatment parameters (Table 4$)$ : volume ( $<30$ vs. $\left.\geq 30 \mathrm{~mm}^{3}\right)$, ID $(<1.4,1.4-2.7,>2.7 \mathrm{~mJ}), \mathrm{D}_{\text {mean }}(<63$ vs. $\geq 63$ Gy), $\mathrm{D}_{\max }(<72$ vs. $\geq 72 \mathrm{~Gy})$, and $\mathrm{PD}$ (<58 vs. $\geq 58$ Gy). Here, only the volume and ID comparisons resulted in significant differences. Patients with volume above $30 \mathrm{~mm}^{3}$ were less likely to experience pain recurrence ( $<30$ vs. $\geq 30 \mathrm{~mm}^{3} ; \mathrm{x}^{2}=4.675, p=0.031$, Table 4; Fig. 4a), while patients with low ID $(<1.4 \mathrm{~mJ})$ tended to suffer more and earlier pain recurrence compared to intermediate (1.4-2.7

Table 3 Summary of actuarial pain control classified on the Barrow Neurological Institute (BNI) pain scale in 231 patients

\begin{tabular}{lll}
\hline BNI grade & $\mathrm{n}$ & $\%$ \\
\hline I & 125 & 54.1 \\
III & 25 & 10.8 \\
IV & 33 & 14.3 \\
V & 22 & 9.5 \\
Total & 26 & 11.3 \\
\hline
\end{tabular}

Grades III a and b were combined
$\mathrm{mJ})$ or high ID $(>2.7 \mathrm{~mJ})$ patients (low vs. intermediate: log-rank test, $\chi^{2}=5.020, p=0.019$; low vs. high: log-rank test, $\chi^{2}=6.026 p=0.014$; Table 5, Fig. 4b).

\section{Occurrence of sensory disturbances}

Re-irradiation using CyberKnife-SRS and presence of MS were independent predictors for the development of bothersome post-treatment numbness in the univariate and multivariate analysis. We also detected a minor but still significant association of isodose in the univariate analysis (Table 6). As with the pain relief analysis, we chose to assess $D_{\text {mean }}$ in the multivariate analysis and had to exclude $D_{\max }$ due to multicollinearity. When patients with re-irradiation and/or MS were excluded, the multivariate model showed slight adjustments in the HR estimators. Isodose became a significant predictor variable with a weak influence (Isodose: $\mathrm{HR}=1.097, \mathrm{CI}=$ 1.004-1.198, $p=0.041$ ).

\section{Discussion}

\section{Key results}

This study was aimed at identifying irradiation parameters that may predict efficacy and safety of image-guided nonisocentric radiosurgery for treatment of TN. For this purpose, we analyzed the impact of target nerve volume, target dose, and the dose/volume relationship, together with relevant clinical characteristics, in a large multicenter German-Italian cohort of patients with a follow-up interval of up to 10 years. As expected, smaller target volume and lower ID were associated with worse pain outcome. In particular, we suggest that a target volume around $30 \mathrm{~mm}^{3}$ and an ID > 1.4 mJ offer better outlooks of sustained pain control. MS as a cause of TN was an independent prognosticator of treatment failure and shorter pain free interval. Furthermore, re-irradiation and presence of MS were independent predictors of the occurrence of numbness.

The results of this series in terms of pain relief are consistent with those previously reported and suggest that image-guided robotic radiosurgery represents an effective treatment of TN $[7,8,10,17]$. Our results are indeed slightly superior to those previously published by Romanelli et al. ( $n=138$ pts.), who reported $76 \%$ pain relief after 3 years compared to $81.4 \%$ in the present cohort [7]. This comparison remained the same with the more recent series by Romanelli et al., with $76 \%$ pain relief at 36 months [27]. Furthermore, we here report results with longer follow-up and describe actuarial pain control rates (BNI class I-III) at 6, 12, 24, 36, 48, and 60 months of $96.8,90.9,84.2,81.4,74.2$, and $71.2 \%$, respectively (Fig. 2). With regard to sensory disturbances, facial numbness was reported by $18 \%$ of patients, with $<1 \%$ reporting bothersome hypoesthesia. Our results are also similar to those published by the two largest studies on GKS [10, 17]. In 


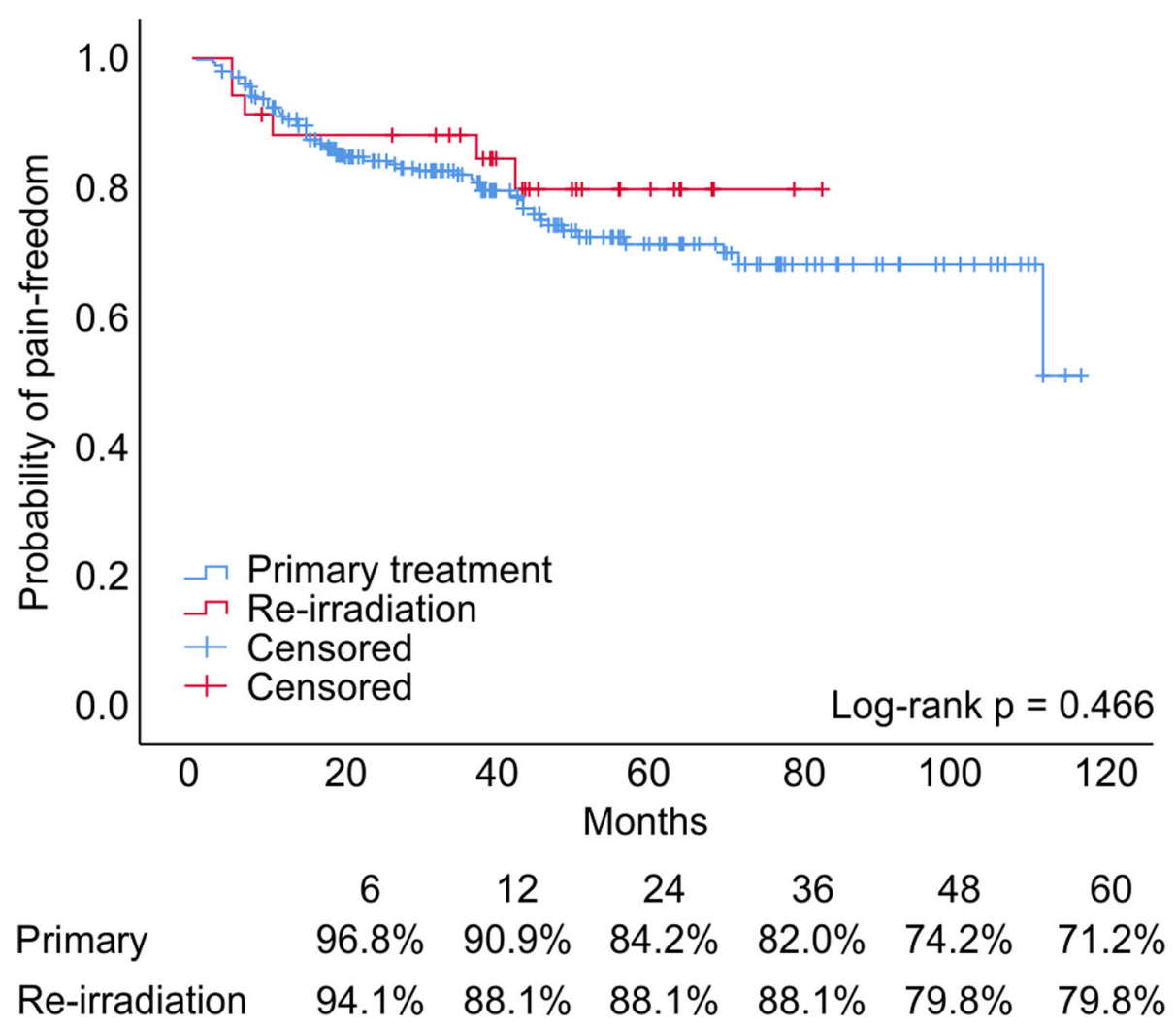

Fig. 3 Pain relief Kaplan Meier curves for primary and re-irradiation treatments

particular, Regis et al. have recently published the long-term results of 497 patients with the probability pain relief at 6 months and $1,2,3,5,7$, and 10 years of $94.3,90.2,87.7,83.6,80.3,75.4$, and $67.7 \%$, respectively, and a rate of new sensory disturbances of $20.4 \%[28]$.

\section{Interpretation}

Tuleasca et al. summarized various treatment regimens regarding dose and target delineation of SRS in the treatment of TN [8]. Romanelli et al. was the first to report the use of frameless and non-isocentric SRS as a treatment option for TN [29]. They reported high

Table 4 Univariate and multivariate Cox regression analyses for factors affecting pain outcome

\begin{tabular}{|c|c|c|c|c|c|c|}
\hline & \multicolumn{3}{|c|}{ Univariate Analyses } & \multicolumn{3}{|c|}{ Multivariate Analysis } \\
\hline & $\mathrm{HR}$ & $95 \% \mathrm{Cl}$ & $p$-value & $\mathrm{HR}$ & $95 \% \mathrm{Cl}$ & $p$-value \\
\hline Age & 0.994 & $0.977-1.011$ & 0.491 & & & \\
\hline Gender & 1.195 & $0.725-1.970$ & 0.484 & & & \\
\hline Volume & 0.956 & $0.933-0.980$ & 0.000 & & & \\
\hline Integral dose & 0.549 & $0.381-0.792$ & 0.001 & 0.540 & $0.376-0.775$ & 0.001 \\
\hline$D_{\text {mean }}$ & 1.027 & $0.987-1.068$ & 0.189 & 1.041 & $1.002-1.080$ & 0.038 \\
\hline Isodose & 0.988 & $0.908-1.075$ & 0.777 & & & \\
\hline$D_{\max }$ & 1.026 & $0.991-1.062$ & 0.150 & & & \\
\hline Prescription dose & 1.578 & $0.984-1.020$ & 0.209 & & & \\
\hline $\begin{array}{l}\text { Re-irradiation } \\
\text { yes/no } \\
\text { no as reference }\end{array}$ & 0.732 & $0.315-1.699$ & 0.467 & & & \\
\hline $\begin{array}{l}\text { Multiple sclerosis } \\
\text { yes/no } \\
\text { no as reference }\end{array}$ & 0.340 & $0.162-0.714$ & 0.004 & 0.332 & $0.156-1.002$ & 0.004 \\
\hline
\end{tabular}



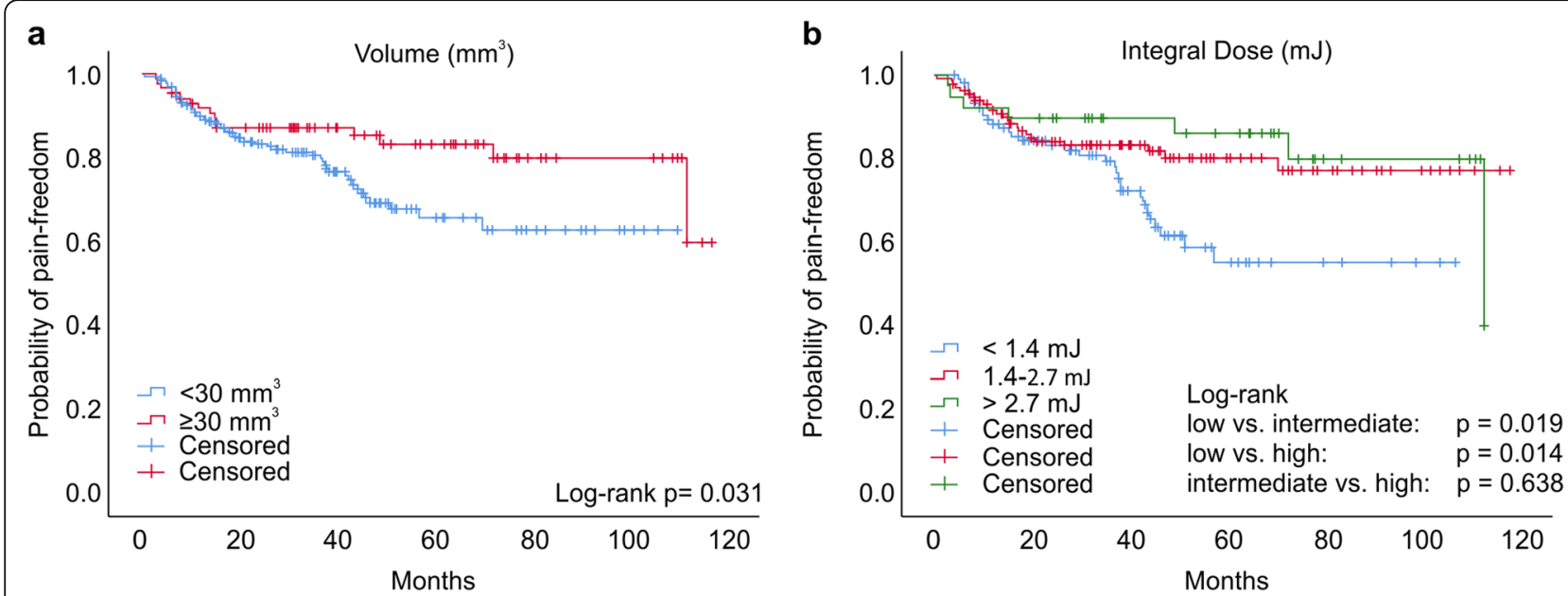

Fig. 4 Kaplan Meier comparisons of pain-freedom probability. a target volume $\left(<30 \mathrm{~mm}^{3}\right.$ vs. $\left.\geq 30 \mathrm{~mm}^{3}\right)$ and (b) integral dose $(<1.4 \mathrm{~mJ}$; $1,4-2,7 \mathrm{~mJ} ;>2,7 \mathrm{~mJ})$

precision and almost immediate pain relief following treatment with a PD between 65 and 70 Gy on a nerve segment up to $11 \mathrm{~mm}$ [29]. However, the irradiation of such long nerve segments led to a significant numbness in these patients; thus, new therapeutic algorithms were explored to identify the best treatment parameters.

In 2008 Villavicencio et al. [22] published the evaluation of 95 patients who were treated using CyberKnifeSRS. The authors included not only heterogeneous treatments in this study concerning dose and target volumes, but also modalities like isocentric and non-isocentric. The median maximal dose used was $75 \mathrm{~Gy}$. Some variables were predictive for pain recurrence, such as median maximum and minimum dose and targeted median nerve length. In this cohort, $50 \%$ of the population had good pain control after 2 years, but $47 \%$ of the patients developed new facial numbness [22]. Thus, the irradiation of a long trigeminal nerve segment led to a very good rate of pain control, but also to a significant risk of facial numbness and suggested the necessity to set precise dose/volume constraints to optimize treatments.
Romanelli et al. have recently found a shorter treated nerve length ( $<6$ vs. $6 \mathrm{~mm}$ ), a smaller treated nerve volume $\left(<30\right.$ vs. $\left.>30 \mathrm{~mm}^{3}\right)$, and a lower PD ( $<58$ vs. $>58$ Gy) as predictors for treatment failure in univariate analysis, while none of these factors remained significant in multivariate analysis [7]. Those results were integrated into a larger and multicentric population of patients to improve the reliability and reproducibility of the findings. In the present univariate analysis, target nerve volume, ID, and presence of MS turned out to be factors associated with pain recurrence. ID and MS also retained significance in the multivariate analysis, while volume could not be included because of high correlation with ID. Our results support the impact of MS on the outcome of patients with $\mathrm{TN}$, consistent with our previous study where only $44 \%$ of patients were painfree for years after therapy [30]. This present study confirmed that patients with nerve volumes $<30 \mathrm{~mm}^{3}$ were more likely to suffer pain relapse. In addition, this was also observed for patients with low ID $(<1.4 \mathrm{~mJ})$. The ID is the product of the mean dose and the target nerve volume and therefore represents an ideal parameter for

Table 5 Comparisons of binarized treatment parameters for the probability of maintaining pain relief

\begin{tabular}{lll}
\hline Variables & $\mathrm{n}$ & $\begin{array}{l}\text { Chi }^{2} \text { and } P \text {-values } \\
\text { Pain }\end{array}$ \\
\hline Volume $\left(<30\right.$ vs. $\left.\geq 30 \mathrm{~mm}^{3}\right)$ & 205 vs. 91 & $x^{2}=4.675, p=0.031$ \\
Integral dose $(<1.4,1.4-2.7,>2.7 \mathrm{~mJ})$ & 114 vs. 144 vs. 39 & $\begin{array}{l}\text { low vs. intermediate: } x^{2}=5.020, p=0.019 \\
\text { low vs. high: } x^{2}=6.026, p=0.014 \\
\text { intermediate vs. high, } x^{2}=0.221, p=0.638\end{array}$ \\
$D_{\operatorname{mean}}(<63$ vs. $\geq 63$ Gy $)$ & & $x^{2}=1.803, p=0.179$ \\
$D_{\max }(<72$ vs. $\geq 72$ Gy $)$ & 75 vs. 221 & $x^{2}=2.756, p=0.097$ \\
Prescriptin dose $(<58$ vs. $\geq 58$ Gy) & 132 vs. 164 & $x^{2}=0.440, p=0.838$
\end{tabular}

$p<0.05$ - significant, log-rank test. $x^{2}$ - test statistic of the $\mathrm{Chi}^{2}$ test 
Table 6 Univariate and multivariate Cox regression analyses for factors affecting the occurrence of numbness

\begin{tabular}{|c|c|c|c|c|c|c|}
\hline & \multicolumn{3}{|c|}{ Univariate Analyses } & \multicolumn{3}{|c|}{ Multivariate Analysis } \\
\hline & $\mathrm{HR}$ & $95 \% \mathrm{Cl}$ & $p$-value & $\mathrm{HR}$ & $95 \% \mathrm{Cl}$ & $p$-value \\
\hline Age & 0.994 & $0.978-1.012$ & 0.519 & & & \\
\hline Gender & 0.906 & $0.566-1.450$ & 0.681 & & & \\
\hline Volume & 0.987 & $0.970-1.005$ & 0.148 & & & \\
\hline Integral dose & 0.787 & $0.594-1.044$ & 0.097 & 0.789 & $0.603-1.033$ & 0.085 \\
\hline$D_{\text {mean }}$ & 0.973 & $0.937-1.010$ & 0.155 & 1.024 & $0.986-1.064$ & 0.214 \\
\hline Isodose & 1.106 & $1.016-1.204$ & 0.021 & 1.072 & $0.978-1.176$ & 0.136 \\
\hline$D_{\max }$ & 0.969 & $0.938-1.002$ & 0.062 & & & \\
\hline Prescription dose & 0.977 & $0.836-1.019$ & 0.281 & & & \\
\hline $\begin{array}{l}\text { Re-irradiation } \\
\text { yes/no } \\
\text { no as reference }\end{array}$ & 4.446 & $2.667-7.412$ & 0.000 & 5.814 & $3.252-10.295$ & 0.000 \\
\hline $\begin{array}{l}\text { Multiple sclerosis } \\
\text { yes/no } \\
\text { no as reference }\end{array}$ & 0.390 & $0.167-0.908$ & 0.024 & 0.196 & $0.079-0.484$ & 0.000 \\
\hline
\end{tabular}

non-isocentric treatments in which not only the dose, but also the target volume can be modulated to fit individual anatomy and clinical objectives. Mousavi et al. [23] investigated 155 patients treated by GKS and reported that the optimal treatment outcome could be achieved by medium IDs $(1.4-2.7 \mathrm{~mJ})$. To be able to compare our cohort with the study by Mousavi et al. [23], we categorized the ID in the same way and observed that the patients with lower IDs (i.e. $<1.4 \mathrm{~mJ}$ ) were more likely to suffer pain relapse. This is in line with our finding that lower ID was an independent predictor for pain recurrence in this analysis. One treatment parameter which has been associated with the clinical outcome, particularly to the risk of sensory disturbance, is the dose received by the brainstem [21, 31].

Finally, we identified re-irradiation as the major independent predictor for sensory disturbance, with almost a six times higher risk after CKS as already described by Romanelli et al. [7] In our univariate analyses, presence of MS and prescription isodose, in addition to reirradiation, were also associated with the development of sensory disturbances, but only re-irradiation and MS retained significance in the multivariate analysis as independent prognostic factors.

\section{Limitations}

Our follow-up length is longer than that of most studies focusing on the efficacy of SRS in TN published so far [9-17], but much longer follow-up periods are needed for a definitive evaluation of the technique. This is indeed essential to provide a valid comparison with MVD. Although we have reported good to excellent outcomes, long-term results up to 10 years later could be disappointing, with up to $60 \%$ pain recurrence rates at a later stage $[17,28,32]$.

\section{Conclusions}

This study represents the largest multicenter frameless CKS series conducted to analyze possible treatment parameters as predictors of outcome in addition to the description of efficacy and safety profile of the technique. Our study confirmed that single treatment parameters are not enough to predict treatment efficacy of SRS in TN. The ID, $\mathrm{D}_{\text {mean }}$, and nerve volume are apparently relevant, as they may differ significantly in treatments using apparently similar dose and volume constraints. Our study supports the concept of personalized radiosurgery for the best treatment outcome and warrants future prospective studies.

\section{Supplementary information}

Supplementary information accompanies this paper at https://doi.org/10. 1186/s13014-020-01535-1.

Additional file 1.

\section{Abbreviations}

SRS: Stereotactic radiosurgery; TN: Trigeminal neuralgia; MS: Multiple sclerosis; BNI: Barrow Neurological Institute; MVD: Microvascular decompression; GKS: Gamma knife radiosurgery; CKS: CyberKnife system; $D_{\text {mean: Mean }}$ treatment dose; $D_{\text {max: }}$ Maximal treatment dose; PD: Prescription dose; ID: Integral dose; CT: Computed tomography; CISS: Co-registered constructive interference in steady state; MR: Magnetic resonance; OAR: Organs at risk; HR: Hazard ratio; Cl: Confidence interval

\section{Acknowledgements}

Dr. Acker is a participant of the BlH-Charité Clinician Scientist Program funded by the Charité - Universitätsmedizin Berlin and the Berlin Institute of Health. 


\section{Authors' contributions}

AC (Conti) and GA acquired, analyzed, and interpreted the patient data, drafted the manuscript. JH conducted the statistical analysis. AK provided technical support, preparation of Figs. AP, AC (Cacciola), GI, MK, GB, SP, AB, FL, SP made substantial contributions to acquisition and provided administrative support. VB and PV critically revised the article. PR and CS participated in the design of the study and made substantial contributions to acquisition, analysis, and interpretation of the data. AC, GA, and CS approved the final version of the manuscript on behalf of all authors. All authors read and approved the final manuscript.

\section{Funding}

None.

\section{Availability of data and materials}

The datasets used and/or analyzed during the current study are available from the corresponding author on reasonable request.

\section{Ethics approval and consent to participate}

The retrospective analysis was approved by the Ethics Committee Campus Charité Mitte (EA1/233/18) and by Comitato Ethico Interaziendale Messina (80/19). Consent to participate is not applicable for a retrospective study.

\section{Consent for publication}

Not applicable.

\section{Competing interests}

There is no conflict of interest concerning the materials or methods used in this study or the findings specified in this paper. Dr. Conti and Dr. Romanelli received research and travel grants from Accuray Inc., Sunnyvale, CA, USA.

\begin{abstract}
Author details
${ }^{1}$ Department of Neurosurgery, Charité - Universitätsmedizin Berlin, corporate member of Freie Universität Berlin, Humboldt-Universität zu Berlin and Berlin Institute of Health, Charitéplatz 1, 10117 Berlin, Germany. ${ }^{2}$ Charité CyberKnife Center, Charité - Universitätsmedizin Berlin, Augustenburger Platz 1, Berlin 13353, Germany. ${ }^{3}$ Unit of Neurosurgery, IRCCS ISNB Istituto delle Scienze Neurologiche di Bologna; Department of Biomedical and Neuromotor Sciences, Alma Mater Studiorum University of Bologna, Bologna, Italy. ${ }^{4}$ Berlin Institute of Health (BIH), Anna-Louisa-Karsch-Str. 2, Berlin 10178, Germany. ${ }^{5}$ Department of Radiation Oncology, University of Messina, Messina, Italy. ${ }^{6}$ Institute of Biometry and Clinical Epidemiology, Charité Universitätsmedizin Berlin AND Berlin Institute of Health , Berlin, Germany. ${ }^{7}$ Clinical Research Unit (CRU), Berlin Institute of Health, Charitéplatz 1, 10117 Berlin, Germany. ${ }^{8}$ Fakultät III, Dep. Information \& Communication, Medical Information Management, Hochschule Hannover - University of Applied Sciences and Arts, Expo Plaza 12, 30539 Hannover, Germany. ${ }^{9}$ Department of Radiation Oncology, Charité - Universitätsmedizin Berlin, Augustenburger Platz 1, 13353 Berlin, Germany. ${ }^{10}$ Brain Radiosurgery, CDI Centro Diagnostico Italiano, Milan, Italy.
\end{abstract}

Received: 13 February 2020 Accepted: 13 April 2020 Published online: 22 May 2020

\section{References}

1. Bennetto $L$, Patel NK, Fuller G. Trigeminal neuralgia and its management. BMJ. 2007;334:201-5.

2. Jannetta PJ. Trigeminal neuralgia. Neurosurgery. 1986;18:677.

3. Jannetta PJ. Outcome after microvascular decompression for typical trigeminal neuralgia, hemifacial spasm, tinnitus, disabling positional vertigo, and glossopharyngeal neuralgia (honored guest lecture). Clin Neurosurg. 1997:44:331-83.

4. Nanda A, Javalkar V, Zhang S, Ahmed O. Long term efficacy and patient satisfaction of microvascular decompression and gamma knife radiosurgery for trigeminal neuralgia. J Clin Neurosci. 2015;22:818-22. https://doi.org/10. 1016/j.jocn.2014.11.028.

5. Tomasello F, Esposito F, Abbritti RV, Angileri FF, Conti A, Cardali SM, et al. Microvascular decompression for trigeminal neuralgia: technical refinement for complication avoidance. World Neurosurg. 2016;94:26-31.
6. Marchetti M, Pinzi V, De Martin E, Ghielmetti F, Fariselli L. Radiosurgery for trigeminal neuralgia: the state of art. Neurol Sci. 2019. https://doi.org/10. 1007/s10072-019-03814-6.

7. Romanelli P, Conti A, Bianchi L, Bergantin A, Martinotti A, Beltramo G Image-guided robotic radiosurgery for trigeminal neuralgia. Neurosurgery. 2018:83:1023-30.

8. Tuleasca C, Regis J, Sahgal A, De Salles A, Hayashi M, Ma L, et al. Stereotactic radiosurgery for trigeminal neuralgia: a systematic review. J Neurosurg. 2018;130:733-57. https://doi.org/10.3171/2017.9.JNS17545.

9. Kondziolka D, Zorro O, Lobato-Polo J, Kano H, Flannery TJ, Flickinger JC, et al. Gamma knife stereotactic radiosurgery for idiopathic trigeminal neuralgia. J Neurosurg. 2010;112:758-65.

10. Marshall K, Chan MD, McCoy TP, Aubuchon AC, Bourland JD, McMullen KP, et al. Predictive variables for the successful treatment of trigeminal neuralgia with gamma knife radiosurgery. Neurosurgery. 2012;70:566-72.

11. Massager N, Lorenzoni J, Devriendt D, Desmedt F, Brotchi J, Levivier M. Gamma knife surgery for idiopathic trigeminal neuralgia performed using a far-anterior cisternal target and a high dose of radiation. J Neurosurg. 2004; 100:597-605.

12. Pollock BE. Fitting radiosurgery into the trigeminal neuralgia management puzzle. World Neurosurg. 2010;74:448-50

13. Regis J, Metellus P, Hayashi M, Roussel P, Donnet A, Bille-Turc F. Prospective controlled trial of gamma knife surgery for essential trigeminal neuralgia. J Neurosurg. 2006;104:913-24.

14. Riesenburger Rl, Hwang SW, Schirmer CM, Zerris V, Wu JK, Mahn K, et al. Outcomes following single-treatment gamma knife surgery for trigeminal neuralgia with a minimum 3-year follow-up. J Neurosurg. 2010;112:766-71.

15. Sheehan J, Pan H-C, Stroila M, Steiner L. Gamma knife surgery for trigeminal neuralgia: outcomes and prognostic factors. J Neurosurg. 2005;102:434-41.

16. Tawk RG, Duffy-Fronckowiak M, Scott BE, Alberico RA, Diaz AZ, Podgorsak $M B$, et al. Stereotactic gamma knife surgery for trigeminal neuralgia: detailed analysis of treatment response. J Neurosurg. 2005;102:442-9.

17. Tuleasca C, Carron R, Resseguier N, Donnet A, Roussel P, Gaudart J, et al. Patterns of pain-free response in 497 cases of classic trigeminal neuralgia treated with gamma knife surgery and followed up for least 1 year. J Neurosurg. 2012;117:181-8. https://doi.org/10.3171/2012.8.GKS121015.

18. Conti A, Pontoriero A, Arpa D, Siragusa C, Tomasello C, Romanelli P, et al. Efficacy and toxicity of CyberKnife re-irradiation and "dose dense" temozolomide for recurrent gliomas. Acta Neurochir. 2012;154:203-9. https://doi.org/10.1007/s00701-011-1184-1.

19. Conti A, Pontoriero A, Ricciardi GK, Granata F, Vinci S, Angileri FF, et al. Integration of functional neuroimaging in CyberKnife radiosurgery: feasibility and dosimetric results. Neurosurg Focus. 2013;34:E5. https://doi.org/10.3171/ 2013.2.FOCUS12414

20. Adler JRJ, Bower R, Gupta G, Lim M, Efron A, Gibbs IC, et al. Nonisocentric radiosurgical rhizotomy for trigeminal neuralgia. Neurosurgery. 2009;64: A84-90.

21. Borchers JD 3rd, Yang HJ, Sakamoto GT, Howes GA, Gupta G, Chang SD, et al. Cyberknife stereotactic radiosurgical rhizotomy for trigeminal neuralgia: anatomic and morphological considerations. Neurosurgery. 2009;64:A91-5.

22. Villavicencio AT, Lim M, Burneikiene S, Romanelli P, Adler JR, McNeely L, et al. Cyberknife radiosurgery for trigeminal neuralgia treatment: a preliminary multicenter experience. Neurosurgery. 2008;62:647-55.

23. Mousavi SH, Niranjan A, Akpinar B, Monaco EA, Cohen J, Bhatnagar J, et al. A proposed plan for personalized radiosurgery in patients with trigeminal neuralgia. J Neurosurg. 2018;128:452-9. https://doi.org/10.3171/2016.10.JNS16747.

24. Wolf A, Tyburczy A, Ye JC, Fatterpekar G, Silverman JS, Kondziolka D. The relationship of dose to nerve volume in predicting pain recurrence after stereotactic radiosurgery in trigeminal neuralgia. J Neurosurg. 2018;128:8916. https://doi.org/10.3171/2016.12.JNS161862.

25. Rogers CL, Shetter AG, Fiedler JA, Smith KA, Han PP, Speiser BL. Gamma knife radiosurgery for trigeminal neuralgia: the initial experience of the Barrow neurological institute. Int J Radiat Oncol Biol Phys. 2000;47:1013-9.

26. Dziodzio T, Jara M, Hardt J, Weiss S, Ritschl PV, Denecke C, et al. Effects of expanded allocation programmes and organ and recipient quality metrics on transplant-related costs in kidney transplantation - an institutional analysis. Transpl Int. 2019:32:1074-84. https://doi.org/10.1111/tri.13463.

27. Romanelli P, Conti A, Redaelli I, Martinotti AS, Bergantin A, Bianchi LC, et al. Cyberknife radiosurgery for trigeminal neuralgia. Cureus. 2019;11:e6014. https://doi.org/10.7759/cureus.6014. 
28. Regis J, Tuleasca C, Resseguier N, Carron R, Donnet A, Gaudart J, et al. Longterm safety and efficacy of gamma knife surgery in classical trigeminal neuralgia: a 497-patient historical cohort study. J Neurosurg. 2016;124:107987. https://doi.org/10.3171/2015.2.JNS142144.

29. Romanelli P, Heit G, Chang SD, Martin D, Pham C, Adler J. Cyberknife radiosurgery for trigeminal neuralgia. Stereotact Funct Neurosurg. 2003;81: $105-9$.

30. Conti A, Pontoriero A, lati G, Esposito F, Siniscalchi EN, Crimi S, et al. Frameless stereotactic radiosurgery for treatment of multiple sclerosisrelated trigeminal neuralgia. World Neurosurg. 2017;103:702-12.

31. Smith ZA, Gorgulho AA, Bezrukiy N, McArthur D, Agazaryan N, Selch MT, et al. Dedicated linear accelerator radiosurgery for trigeminal neuralgia: a single-center experience in 179 patients with varied dose prescriptions and treatment plans. Int J Radiat Oncol Biol Phys. 2011;81:225-31.

32. Regis J, Tuleasca C, Resseguier N, Carron R, Donnet A, Yomo S, et al. The very long-term outcome of radiosurgery for classical trigeminal neuralgia. Stereotact Funct Neurosurg. 2016;94:24-32. https://doi.org/10.1159/ 000443529 .

\section{Publisher's Note}

Springer Nature remains neutral with regard to jurisdictional claims in published maps and institutional affiliations.

Ready to submit your research? Choose BMC and benefit from:

- fast, convenient online submission

- thorough peer review by experienced researchers in your field

- rapid publication on acceptance

- support for research data, including large and complex data types

- gold Open Access which fosters wider collaboration and increased citations

- maximum visibility for your research: over $100 \mathrm{M}$ website views per year

At BMC, research is always in progress.

Learn more biomedcentral.com/submissions 